\title{
UPAYA MENINGKATKAN HASIL BELAJAR SISWA DALAM PEMBELAJARAN IPA MELALUI KOOPERATIF THINK, PAIR, SHARE (TPS) PADA SISWA KELAS IV SDN 010214 TANAH MERAH
}

\author{
Irwansyah \\ Surel: iirwan135@gmail.com
}

\begin{abstract}
ABSTRAK
Penelitian ini bertujuan untuk meningkatkan aktifitas dan hasil belajar siswa dengan menggunakan model koopertif Think, Pair, Share. Objek penelitian ini adalah siswa kelas IV SDN 010214 Tanah Merah yang terdiri dari 40 siswa. Pada saat siklus I pada pelajaran IPA nilai rata-rata siswa 64,28 dan yang tuntas 55\% setelah dilakukan tindakan yaitu pada siklus II mengalami peningkatan yakni nilai rata-rata siswa memningkat signifikan menjadi 80 dan yang tuntas $96 \%$. Hal ini menyatakan bahwa pengunaan model kooperatif Think, Pair, Share (TPS) dapat meningkatkan hasil belajar siswa.
\end{abstract}

Kata Kunci : Hasil Belajar, Koopertif, Think-Pair-Share

\section{PENDAHULUAN}

Pendidikan merupakan salah satu kebutuhan manusia. Pendidikan tidak dapat diperoleh begitu saja dalam waktu yang singkat, namun memerlukan suatu proses pembelajaran sehingga menimbulkan hasil atau efek yang sesuai dengan proses yang telah dilalui tersebut. Sumber daya manusia yang berpendidikan akan mampu mengikut perkembangan Ilmu Pengetahuan dan Teknologi (IPTEK). Berbagai usaha dilakukan oleh pemerintah dalam rangka meningkatkan mutu pendidikan di Indonesia salah satunya adalah dengan menetapkan Kurikulum Tingkat Satuan Pendidikan (KTSP) sesuai dengan peraturan menteri pendidikan No. 22, 23 dan 24 Tahun 2005.

Rendahnya tingkat pendidikan ini dapat disebabkan oleh berbagai faktor diantaranya faktor-faktor yang berasal dari dalam diri siswa dan dari luar diri siswa. Faktor yang berasal dari dalam diri siswa meliputi kemampuan, kesiapan, sikap, minat dan intelijensi. Faktor yang berasal dari luar diri siswa adalah guru, prasarana, dan lingkungan. Rendahnya hasil belajar diakibatkan oleh pengaruh strategi pembelajaran yang kurang menarik dan terkesan sulit, sehingga siswa lebih dahulu merasa jenuh sebelum mempelajarinya. Hasil belajar itu dikatakan rendah apabila nilainya dibawah KKM bidang studi yang sudah ditentukan. Dari hasil observasi yang dilakukan peneliti, metode pembelajaran IPA yang diterapkan oleh guru seringkali adalah metode ceramah. Hal ini terlihat dari RPP (Rencana Pelaksanaan Pembelajaran) yang banyak menggunakan metode ceramah. Metode ini membuat guru mendominasi kegiatan belajar 
mengajar dikelas sehingga siswa menjadi pasif. Guru dijadikan sebagai satu-satunya sumber informasi sehingga kegiatan pembelajaran hanya mengutamakan aspek kognitif tanpa memperhatikan aspek afektif dan psikomotorik. Dan dari hal diatas banyak siswa yang memiliki hasil belajar rendah.

Dari hal tersebutlah yang mendorong penulis untuk melakukan perbaikan hasil belajar siswa yakni dengan melakukan penelitian tindakan kelas dengan menggunakan Kooperatif Think, Pair, Share.

Berdasarkan dari latar belakang diatas dapat di identifikasi beberapa masalah antara lain:

1. Rendahnya hasil belajar IPA siswa kelas IV SD Negeri 010214 Tanah Merah.

2. Keaktifan siswa dalam proses belajar mengajar masih kurang.

3. Rendahnya minat belajar siswa

4. Metode atau pendekatan pembelajaran yang digunakan belum sesuai dengan pembelajaran yang disampaikan.

Sejumlah masalah pembelajaran di atas terkait dengan belum adanya pengolahan pembelajaran di kelas sehingga aktivitas siswa belum nampak untuk belajar.beberapa penyebab rendahnya hasil belajar siswa pada pelajaran IPA adalah:

a. Dalam kegiatan belajar mengajar tidak menggunakan metode pembelajaran sehingga aktivitas siswa masih rendah.

b. Menyampaikan materi pembelajaran hanya menggunakan metode ceramah yang memungkinkan aktivitas siswa tidak muncul mereka hanya mendengarkan saja.

Selain metode atau model pembelajaran keaktifan siswa juga ditentukan oleh pengunaan strategi pembelajaran. Maka dengan menggunakan Strategi kooperatif akan menuntut siswa aktif dalam diskusi dalam kegitan pembelajaran serta nantinya akan meningkatkan hasil belajar siswa.

Berdasarkan hasil analisa penyebab kurangnya aktifvitas siswa untuk belajar adalah kurangnya penggunaan variasi mengajar yang dapat diamati langsung dalam pembelajaran. Maka dengan demikian yang menjadi fokus perbaikan dalam kegiatan pembelajaran IPA dikelas IV SDN 010214 Tanah Merah adalah "Bagaimanakah meningkatkan Hasil Belajar siswa dalam pembelajaran IPA dengan menggunakan Kooperatif TPS".

Tujuan perbaikan dilakukan penulis dalam pembelajaran IPA adalah dengan:

1. Mengidentifikasi dan mengamati pelajaran IPA yang terjadi di kelas.

2. Meningkatkan Aktifvitas belajar siswa dengan menggunakan Kooperatif TPS.

Adapun manfaat penelitian ini ialah:

1. Bagi guru

- Menjadi bahan informasi yang berguna untuk meningkatkan kompetensi pembelajaran. 


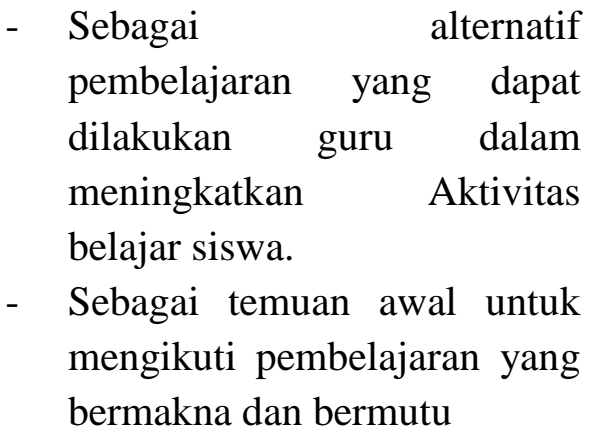
Bagi siswa

- Membuka peluang untuk mengikuti pembelajaran yang bermakna dan bermutu.

- Mampu meningkatkan Aktifvitas belajar siswa

2. Bagi Sekolah.

- Membuka kesempatan untuk memiliki guru-guru yang berkompeten, profesional dan mampu meningkatkan mutu pendidikan disekolah.

\section{METODE PENELITIAN}

Subjek dalam penelitian ini adalah siswa kelas IV SDN 010214 Tanah merah Kecamatan Air Putih Kabupaten Batubara yang berjumlah 40 orang. Penelitian ini dilaksanakan di SDN 010214 Tanah Merah Jalan Pasar 1 Simpang Empat Kecamatan Air Putih Kabupaten Batubara. Penelitian ini berlangsung pada tanggal 21 Agustus 2013 untuk pelaksanaan siklus 1 dan 28 Agustus 2013 untuk pelaksanaan siklus II.

Penelitian yang dilakukan adalah penelitian tindakan kelas dalam bentuk siklus, seperti ditunjukkan dalam Gambar 3.1:
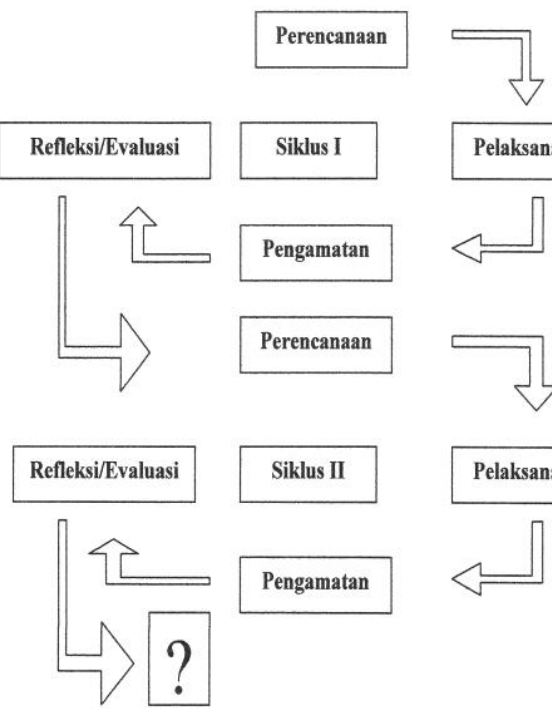

Siklus II
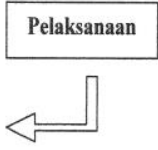

Pengamatan

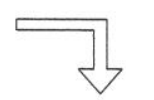

Gambar 3.1 Langkah-Langkah

Penelitian Tindakan Kelas

Adapun perencanaan yang dilakukan adalah sebagai berikut :

a. Melakukan pra observasi.

- Membuat skenario pelaksanaan tindakan pada pengajaran IPA dengan Model TPS.

- Membuat lembar observasi instruktur untuk mengamati bagaimana kondisi proses belajar mengajar mata pelajaran IPA.

- Menyusun instrumen tes untuk mengetahui kemampuan anak sebelum dan sesudah diberikan tindakan.

- Melaksanakan uji coba instrumen tes .

- Memberikan tes awal kemampuan IPA. Hal ini untuk mengetahui kemampuan awal anak sebelum diberi tindakan. 
b. Melakukan observasi instruktur kemampuan anak pada setiap kegiatan dan pada setiap pertemuan proses belajar mengajar mata pelajaran IPA di dalam kelas.

c. Memberikan tes kemampuan IPA secara individual pada setiap siklus dan menganalisis hasil tes tersebut untuk mengetahui perkembangan kemampuan IPA anak setelah diberi tindakan.

Kegiatan yang dilaksanakan dalam tahap ini adalah melaksanakan skenario pelaksanaan tindakan yang telah tersusun, dengan menggunakan Model TPS dalam menyajikan materi pelajaran tentang IPA .

Pada tahap ini dilaksanakan tahap observasi terhadap pelaksanaan tindakan dengan menggunakan lembar observasi terstruktur. Observasi dilakukan untuk mengamati kemampuan anak pada setiap tindakan yang diberikan pada setiap proses belajar mengajar mata pelajaran IPA di dalam kelas.

Penelitian dalam melakukan observasi ini dibantu oleh seorang observer yaitu guru kelas V SD Negeri No. 010214 Tanah Merah.

Hasil yang diperoleh pada tahap observasi dan evaluasi kemampuan IPA melalui tes lisan dikumpulkan dan dari evaluasi tersebut penelitian dapat merefleksi, apakah kegiatan yang telah dilakukan sudah dapat meningkatkan kemampuan siswa atau belum. Artinya jika hasil tes kemampuan IPA berdasarkan kriteria penilaian kemampuan belum mencapai indikator keberhasilan yang sudah ditentukan oleh guru (peneliti) yaitu $70 \%$ anak belum memperoleh nilai 65 ke atas, maka penelitian tindakan dilanjutkan pada siklus berikutnya. Namun jika hasil tes kemampuan IPA sudah mencapai indikator keberhasilan yang sudah ditentukan oleh guru (peneliti) yaitu $70 \%$ anak sudah memperoleh nilai 65 ke atas maka penelitian tindakan dihentikan. data:

Langkah-langkah pengolahan

a. Mentabulasi data skor dari tiap siswa skala 1-100 dengan rumus sebagai berikut :

$\frac{\text { Skor yang diperoleh }}{\text { | Jumlah Soal }} \times 100$

Tabel 3.3. Tabulasi Atas dan Nilai dari Setiap Kelas

\begin{tabular}{|l|l|l|}
\hline No & Nama Siswa & Nilai \\
\hline & & \\
\hline
\end{tabular}

b. Membuat Frekuensi Nilai dari Setiap Kelas

Tabel 3.4. Frekuensi Nilai dari

\begin{tabular}{|l|l|l|l|}
\multicolumn{2}{|c}{ Setiap Kelas } \\
\hline \multirow{2}{*}{ No } & \multirow{2}{*}{ Nilai } & \multicolumn{2}{|c|}{ Frekuensi } \\
\cline { 3 - 4 } & & Absolut & Relatif \\
\hline & & & \\
\hline
\end{tabular}

c. Menghitung rata-rata setiap kelas dimana skor rata-rata:

$$
\bar{X}=\frac{\sum f_{i} x_{i}}{\sum f_{i}}(\text { Sudjana 2002) }
$$

Keterangan :

$\bar{X}$ : Rata-rata skor

Xi : Jumlah skor 
fi : Frekuensi

\section{HASIL DAN PEMBAHASAN}

Siklus I

Data Hasil belajar yang diperoleh dari nilai pembelajaran
Matematika pada siklus I dan II. Hal tersebut dapat dilihat dari tabel 4.1 nilai siswa kelas V SDN 010214 Tanah Merah Kecamatan Air Putih Kabupaten Batubara.

Data Hasil Belajar Siswa

\begin{tabular}{|c|c|c|c|c|c|c|c|}
\hline \multirow{2}{*}{ No } & \multirow{2}{*}{ Nama Siswa } & \multicolumn{2}{|c|}{ Siklus I } & \multirow[b]{2}{*}{ Keterangan } & \multicolumn{2}{|c|}{ Siklus II } & \multirow[b]{2}{*}{ Keterangan } \\
\hline & & Skor & Nilai & & Skor & Nilai & \\
\hline 1. & Agung Dewa & 16 & 76.19 & Tuntas & 17 & 85 & Tuntas \\
\hline 2. & Alpi Randa & 17 & 80.95 & Tuntas & 22 & 85 & Tuntas \\
\hline 3. & Ayu Masdinar & 13 & 61.90 & Tidak tuntas & 15 & 75 & Tuntas \\
\hline 4. & Ayu Rizqi & 15 & 71.42 & Tuntas & 17 & 80 & Tuntas \\
\hline 5 & Bahrial & 17 & 80.95 & Tuntas & 17 & 85 & Tuntas \\
\hline 6 & Dandi & 15 & 71.42 & Tuntas & 16 & 80 & Tuntas \\
\hline 7 & Dinda Bunga Arini & 17 & 80.95 & Tuntas & 18 & 90 & Tuntas \\
\hline 8 & Erni Sartika & 13 & 61.90 & Tidak tuntas & 14 & 75 & Tuntas \\
\hline 9 & Fajar Rizki & 12 & 57.14 & Tidak tuntas & 14 & 70 & Tuntas \\
\hline 10 & Faradilla Amalia & 16 & 76.19 & Tuntas & 17 & 85 & Tuntas \\
\hline 11 & Fatimah Nazmi & 13 & 61.90 & Tidak tuntas & 14 & 65 & Tidak tuntas \\
\hline 12 & Ferih & 10 & 47.61 & Tidak tuntas & 15 & 75 & Tuntas \\
\hline 13 & Fitrah Qalbi Srg & 10 & 47.61 & Tidak tuntas & 14 & 70 & Tuntas \\
\hline 14 & Iqbal Andika & 16 & 76.19 & Tuntas & 17 & 85 & Tuntas \\
\hline 15 & Inda Difebrina & 15 & 71.42 & Tuntas & 14 & 70 & Tuntas \\
\hline 16 & Lidya Novita Sari & 16 & 76.19 & Tuntas & 18 & 90 & Tuntas \\
\hline 17 & Mardiah & 15 & 71.42 & Tuntas & 16 & 80 & Tuntas \\
\hline 18 & Miftahul Jannah & 13 & 61.90 & Tidak tuntas & 15 & 75 & Tuntas \\
\hline 19 & Miranti Indah P. & 12 & 57.14 & Tidak tuntas & 15 & 80 & Tuntas \\
\hline 20 & M. Aldi & 15 & 71.42 & Tuntas & 16 & 80 & Tuntas \\
\hline
\end{tabular}


ESJ VOLUME 5, NO. 2, JUNI 2016

\begin{tabular}{|c|c|c|c|c|c|c|c|}
\hline 21 & M. Fikri Hsb & 13 & 61.90 & Tidak tuntas & 15 & 75 & Tuntas \\
\hline 22 & M. Kurniawan & 15 & 71.42 & Tuntas & 16 & 80 & Tuntas \\
\hline 23 & M. Reza & 16 & 76.19 & Tuntas & 17 & 85 & Tuntas \\
\hline 24 & Nur Fadillah & 16 & 76.19 & Tuntas & 17 & 85 & Tuntas \\
\hline 25 & Nurul Khairani Nst & 16 & 76.19 & Tuntas & 17 & 85 & Tuntas \\
\hline 26 & Raoul Rifqi & 12 & 57.14 & Tidak tuntas & 14 & 65 & Tidak tuntas \\
\hline 27 & Rizki Firmansyah & 15 & 71.42 & Tuntas & 17 & 85 & Tuntas \\
\hline 28 & Siti Nurhalizah Nst & 15 & 71.42 & Tuntas & 17 & 85 & Tuntas \\
\hline 29 & Siti Nuraini & 15 & 71.42 & Tuntas & 16 & 80 & Tuntas \\
\hline 30 & Siti Ramadani & 13 & 61.90 & Tidak tuntas & 15 & 75 & Tuntas \\
\hline 31 & Soraya Aurelia & 15 & 71.42 & Tuntas & 16 & 80 & Tuntas \\
\hline 32 & Suharianti & 15 & 71.42 & Tuntas & 16 & 80 & Tuntas \\
\hline 33 & Sunia Wisriani & 13 & 61.90 & Tidak tuntas & 15 & 75 & Tuntas \\
\hline 34 & Syah Rina Yasheh & 16 & 76.19 & Tuntas & 17 & 85 & Tuntas \\
\hline 35 & Tasya Fahira & 13 & 61.90 & Tidak untas & 15 & 80 & Tuntas \\
\hline 36 & Tia wati lubis & 15 & 71.42 & Tuntas & 16 & 80 & Tuntas \\
\hline 37 & Tri Yogi Syaputra & 16 & 76.19 & Tuntas & 18 & 90 & Tuntas \\
\hline 38 & Venny Fiorentina & 13 & 61.90 & Ttidak untas & 15 & 75 & Tuntas \\
\hline 39 & Wahab Ali Nst & 13 & 61.90 & Tidak tuntas & 18 & 90 & Tuntas \\
\hline 40 & Yenni Florentina & 12 & 57.14 & Tidak tuntas & 15 & 75 & Tuntas \\
\hline
\end{tabular}

Dari data di atas dapat diperoleh data bahwa:

Tabel 4.2 Tes Hasil Belajar Siswa Siklus I

\begin{tabular}{|l|c|}
\hline \multicolumn{1}{|c|}{ Keterangan } & Test \\
\hline Nilai Tertinggi & 80.95 \\
\hline Nilai Terendah & 47.61 \\
\hline Nilai Rata-rata & 64.28 \\
\hline $\begin{array}{l}\text { Ketuntasan Klasikal } \\
\text { Belajar siswa }\end{array}$ & $55 \%$ \\
\hline
\end{tabular}

Tabel 4.2 Tes Hasil Belajar Siswa Siklus II

\begin{tabular}{|c|c|}
\hline Keterangan & Test \\
\hline Nilai Tertinggi & 90 \\
\hline Nilai Terendah & 70 \\
\hline Nilai Rata-rata & 80 \\
\hline $\begin{array}{c}\text { Ketuntasan Klasikal } \\
\text { Belajar siswa }\end{array}$ & $95 \%$ \\
\hline
\end{tabular}

Sehingga jelas kelihatan dalam pembelajaran mengunakan TPS dapat 
meningkatkan aktivitas dan hasil belajar siswa Pada siklus I terlihat ketuntasan klisikal belajar siswa 55\% namun pada siklus II setelah diberi tindakan ketuntasan klasikal belajar siswa $95 \%$.

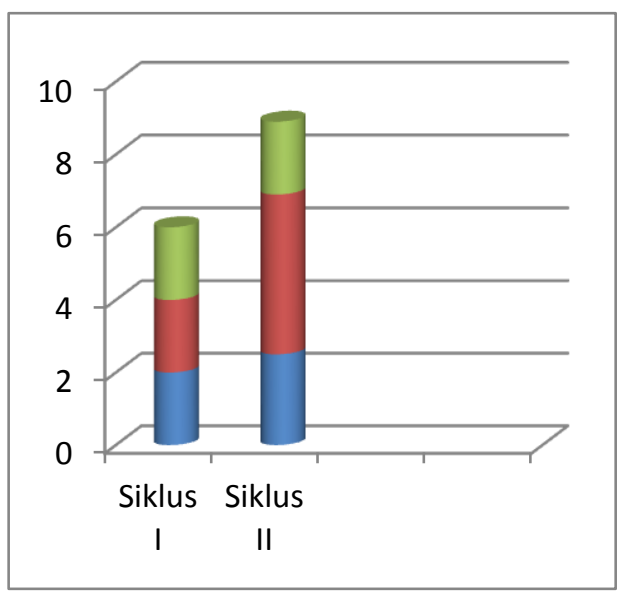

Grafik Hasil ketuntasan belajar siswa siklus I dan siklus II pada pembelajaran IPA.

\section{Pembahasan}

Dari Pengolahan data hasil belajar siswa pada siklus I dan Siklus II dapat di jabarkan dengan tabel sebagai berikut:

\begin{tabular}{|c|l|c|c|}
\hline No & $\begin{array}{l}\text { Pencapaian Hasil } \\
\text { Belajar }\end{array}$ & $\begin{array}{c}\text { Siklus } \\
\text { I }\end{array}$ & $\begin{array}{c}\text { Siklus } \\
\text { II }\end{array}$ \\
\hline 1 & $\begin{array}{l}\text { Jumlah siswa } \\
\text { yang tuntas }\end{array}$ & 24 & 38 \\
\hline 2 & $\begin{array}{l}\text { Jumlah siswa } \\
\text { yang tidak tuntas }\end{array}$ & 16 & 2 \\
\hline 3 & Nilai rata - rata & 64,28 & 80, \\
\hline 4 & $\begin{array}{l}\text { Persentase } \\
\text { ketuntasan }\end{array}$ & $55 \%$ & $95 \%$ \\
\hline
\end{tabular}

Dari tabel diatas dapat dilihat bahwa siswa yang tuntas pada siklus I pembelajaran IPA hanya 24 siswa (55\%) dan di siklus II IPA ada peningkatan yakni siswa yang tuntas berjumlah 38 siswa (95\%). Jadi ada peningkatan hasil belajar siswa dengan dibelajarkan model Kooperatif TPS dengan kenaikan $40 \%$.

\section{KESIMPULAN}

Dari hasil pembahasan dan pengamatan maka diperoleh beberapa kesimpulan sebagai berikut:

1. Sebelum diberi tindakan kesulitan yang dialami siswa adalah memahami pelajaran dan Aktifvitas siswa cenderung kurang muncul.

2. Pada saat siklus I pada pelajaran IPA nilai rata-rata siswa 64,28 dan yang tuntas $55 \%$ setelah dilakukan tindakan yaitu pada siklus II mengalami peningkatan yakni nilai rata-rata menjadi 80 dan yang tuntas $96 \%$.

3. Penerapan model Kooperatif TPS dapat meningkatkan hasil belajar siswa kelas IV SDN 010214 Tanah Merah.

Dari hasil penulisan dan kesimpulan diatas maka penulis mengajukan beberapa saran:

1. Bagi guru: khususnya guru kelas di SD diharapkan menerapakan model atau media dalam pembelajaran salah satunya menggunakan Model kooperatif TPS agar aktifvitas dan hasil belajar siswa meningkat.

2. Bagi siswa: diharapkan agar lebih banyak melakukan latihan dan pengamatan dalam pembelajaran khususnya IPA.

3. Bagi sekolah: diharapkan agar menaungi dan memfasilitasi 
kegiatan pembelajaran secara maksimal khususnya dalam mengadakan pendekatan, strategi, model atau media agar terwujud tujuan pendidikan yang baik di lingkungan dan negara kita.

\section{DAFTAR RUJUKAN}

Abdurahman. 2009. Belajar Mengajar. Rineka Cipta: Jakarta.

Arend. 2005. Belajar dan Pembelajaran. Bandung: Angkasa.

Departemen Pendidikan Nasional. 2007. UU RI No 22 tahun 2005. Jakarta: Depdiknas.

Dimyati. 2006. Pengantar Metode Researe. Bandung: Alumni.

Haryanto. 2007. Ilmu Pengetahuan Alam Kelas 5 SD. Jakarta: Tim Bima Karya Guru Erlangga.

S, Nasution. 2002. Strategi Belajar Mengajar MIP. Malang: Universitas Negeri Malang.
Slameto. 2010. Belajar dan Fakto-

Faktor yang

Mempengaruhinya. Cet. 5.

Jakarta: PT Rineka Cipta.

Sudjana, 2002. Metode Statistika. Ed. rev, cet. 6. Bandung: Tarsito

Sudjana, N. 2008. Penilaian Hasil

Proses Belajar Mengajar.

Bandung: Remaja

Rosdakarya.

Suprijono. 2010. Cooperatif Learning. $\quad$ Yogyakarta: Pustaka Pelajar.

Wardani dkk. 2008. Pemantapan Kemampuan Profesional Buku Panduan. Jakarta: Universitas Terbuka.

Wardani dkk. 2007. Penelitian Tindakan Kelas. Jakarta: Universitas Terbuka. 